PF 2019 (LXXIV): 401-410

\author{
ZBIGNIEW GREŃ \\ Instytut Slawistyki Zachodniej i Południowej \\ Wydział Polonistyki \\ Uniwersytet Warszawski \\ ul. Krakowskie Przedmieście 26/28 \\ 00-927 Warszawa \\ tel. +48225520546 \\ e-mail: zbigniew.gren@uw.edu.pl
}

\title{
GWARY ŚLĄSKA CIESZYŃSKIEGO W INTERNECIE
}

SŁOWA KLUCZOWE: gwara, Śląsk Cieszyński, Internet.

KEYWORDS: dialect, Cieszyn Silesia, Internet.

\section{DIALECTS OF CIESZYN SILESIA ON THE INTERNET}

\begin{abstract}
The aim of the article is to analyze the functioning of Cieszyn dialects on the Internet. On the one hand, we want to describe the functions that this code fulfills, both in primary and secondary use, and to provide a general formal analysis of dialectal statements and statements with different number of dialectal elements, on the other. The dialectal texts and the texts with dialectal elements show a wide variety, both in terms of functionality and form. These are both written texts strictly edited and texts formulated ad hoc, sometimes even spontaneously. At the same time, due to the relatively high anonymity of spontaneous statements, they can naturally reveal the real knowledge and functional use of this code by different users.
\end{abstract}

Materiał językowy uzyskano z cieszyńskich stron regionalnych, po obu stronach Olzy ${ }^{1}$. Analizie korpusu tekstowego z obu stron rzeki granicznej towarzyszyć musi świadomość różnic w rozwoju formalnym gwary wschodnio- i zachodniocieszyńskiej, oraz rozdzielonej granicą gwary południowocieszyńskiej, po podziale Śląska Cieszyńskiego, a co za tym idzie, innego usytuowania funkcjonalnego

1 Zob. analizę obecności w Internecie tematyki lokalnej i regionalnej dla całego Śląska, Greń (2008). 
wśród konkurujących z gwarą kodów: po stronie polskiej jest to standard ogólnopolski, po czeskiej, ogólnopolski i czeski, w jego zróżnicowaniu odmianowym. W rezultacie kod gwarowy spełnia różne funkcje w społeczności autochtonów po obu stronach Olzy - w części czeskiej najczęściej jest kodem podstawowym, w polskiej przechodzi, a w wypadku młodzieży najczęściej już przeszedł do roli kodu sekundarnego, zob. Greń (1997).

W opisie funkcjonalnym winniśmy wyjść od określenia miejsca wypowiedzi gwarowych na osi: teksty oficjalne (/urzędowe) : teksty nieoficjalne (/prywatne). Jest zrozumiałe, że kod gwarowy jest raczej predestynowany do wykorzystania $\mathrm{w}$ wypowiedziach nieoficjalnych. W związku z procesem oficjalizacji (górno)śląszczyzny na Śląsku Górnym należy się liczyć z próbami użyć oficjalnych i w Internecie, por. np. Greń (2008), Mętrak (2014). Przykłady takich prób na Śląsku opisano swego czasu, zob. Greń (2007), z reguły jednak dotyczyło to Śląska Górnego w dzisiejszym rozumieniu potocznym (a więc bez Śląska Cieszyńskiego). Eksploracja Internetu przeprowadzona obecnie nadal nie wskazuje na to, aby śląszczyzna w wariancie cieszyńskim była wykorzystywana w użyciu oficjalnym, por. Greń (2008). Nie oznacza to jednak, że nie ma jej na portalach noszących cechy oficjalne. Jej pojawienie się na nich ma charakter prezentacji utworu uznanego za gwarowy, czy też, krótszego lub dłuższego cytatu, w ramach opisu sporządzonego w polskim języku standardowym (czasem z cechami regionalnymi). Porównajmy przykłady tekstów o charakterze informacyjnym z portalu Śląska Cieszyńskiego www.ox.pl:

W poniedziałek (5 września) w Domu Narodowym w Cieszynie odbyło się spotkanie sekcji miłośników gwary cieszyńskiej „Rzóndzymy, rozprawiomy i śpiywómy po naszymu i ni jyny" (https://wiadomosci.ox.pl/spotkanie...);

W czwartek 7 czerwca 2018 roku w Izbie Regionalnej Wsi Cieszyńskiej w Kończycach Małych po raz ósmy odbył się Powiatowy Konkurs Gwary Śląska Cieszyńskiego rzóndzymy po naszymu (https://wiadomosci.ox.pl/konkurs...);

Konkurs gwar: znamy wyniki! [...] Wyniki: W kategorii 3-6 lat: I miejsce - Aleksander Szuścik z Zebrzydowic - „Robotny ogrómnie” II miejsce - Nadia Koterzyna „Goiczorki” Przedszkole nr 6 w Ustroniu II miejsce - Lena Jaworska "Cieszyńsko suknia” Przedszkole nr 6 w Ustroniu II miejsce - Martyna Armata "Świynto starzików" Przedszkole nr 6 w Ustroniu III miejsce - Zuzanna Donczew „Ustrónioczka” Przedszkole nr 1 w Ustroniu Wyróżnienie: Oskar Martynek „Starość” Przedszkole nr 1 w Ustroniu Zosia Puzoń „Zygor”- nagroda specjalna dla najmłodszej uczestniczki konkursu 3-latki Przedszkole nr 1 w Ustroniu (https://wiadomosci. ox.pl/konkurs-gwar-znamy... ).

Znamię oficjalności noszą teksty literackie i paraliterackie, w tym i folklorystyczne, pisane gwarą, a publikowane w Internecie. Paralelne do nich są teksty publikowane $\mathrm{w}$ mediach tradycyjnych, a reprodukowane $\mathrm{w}$ Internecie. Oto 
fragment krótkiej opowieści, z internetowej reprodukcji pisma „Zwrot”, numer „niedziela, 21.10.2018 (...)":

Trucina (po naszymu) / Byli dwo Jackowie, hónorowi, jak se patrziło na sklepikorzów, czili kaufmanów. Nimieli se moc radzi, bo se kapke kónkurowali. Co sprzedowali, je już po rokach jedno, ale w każdym przipadku ni mieli głymboko do kapsy. / Piyrszi kaufmann se móg nazywać Maks a tyn drugi Izydor. Maks mioł pieknóm babe, za kieróm se wszyscy chłopi łoglóndali, Izydor zaś takóm prałobyczajnóm. [...] (http://zwrot.cz...).

Czasem tekstom udostępnianym oryginalnie w Internecie towarzyszy przekład na język ogólnopolski, co w tekstach reprodukowanych raczej się nie zdarza.

Starzi ludzie to nie były taki móndroki jako wy młodzi; w prostocie ducha poradzili i strómu, i skały poćiuwać, coby yny prawily prowdym. Ći ci nie wśiecko jedno, kiery prowdym rzóndzi i skiyl un? / Sokrates z Atyn // Dawni ludzie nie byli tacy mądrzy jak wy młodzi; w prostocie ducha umieli i dębu, i głazu posłuchać, byleby tylko prawdę mówił. Czyż ci nie wszystko jedno, kto mówi prawdę i skąd on? / Sokrates (http://www.radioistebna.pl/kultura...).

Podobnie na portalu www.gazetacodzienna.pl : Co tydziyń po naszymu: $z$ naszygo na nasze / Kącik gwarowy - 16 kwietnia 2011 09:00:00

F.J.Dral / Po naszymu / Miało się ku obiadu, kiej ciotka Łacioczka zezdrziła przez okno Swojigo, jak się szelónce cestóm od stawu ku chałupie. / Tak się zachruziła, że ji aji różaniec wyszpyltnół się z rónk.(...) // Po polsku / Zbliżała się pora obiadowa, gdy ciotka Łacioczka przez okno męża zobaczyła, jak zatacza się od stawu ku chałupie. / Tak się zdziwiła, że nawet różaniec wyślizgnął się jej z rąk. (...) / Listopad 2001 (http://gazetacodzienna.pl/node...).

Na cieszyńskim portalu regionalnym www.gazetacodzienna.pl funkcjonuje wspomniana wyżej stała rubryka gwarowa, Co tydziyń po naszymu, w której najczęściej pojawia się nie przekład, lecz pomoc w postaci słownika cieszyńsko-ogólnopolskiego, porównajmy fragment opowieści gwarą:

Zwyrtać pedajlami / Doczkołech sie doś wartko tego, coby uwidzieć jak funguje ta nowo scyna na kolcach, bo w zeszłym tydniu uż zustała rozpostrzóno. Gónitwy było na ni co nie miara, bo kierysi mioł taki napad, coby nasze dziecka uczyć tam ekologije. Żodyn jednakowóż mie nie posłóchnył, coby te scyne przesmyczyć na drugóm stróne rynku i zrobić wygode dlo tych co siedzeli ze zadku. [...].

Do tekstu dołączono Minisłownik:

coby-żeby, / funguje-funkcjonuje, / kolca-koła, / rozpostrzóno-rozciągnięta, / napad-pomysł, / przesmyczyć-przeciągnąć, / podarziło-udało się, / skyrs-z powodu, / dycki-wciąż, / pokuta-kara, / koło-rower, / zico-siodełko, / wolant-kierownica, / gesztel-konstrukcja, / zwyrtać-kręcić, / napad-pomysł, / dłażka-podloga, / werk-fabryka (http://gazetacodzienna...). 
Rubryka ta często prowokuje dyskusję, prowadzoną w gwarze cieszyńskiej, czasami i sama treść dotyczy form gwarowych. Porównajmy wątek: Co tydziyń po naszymu: Ausdruki, czyli powiedzonka / Kącik gwarowy - 26 luty 2011 10:00:00, który sprowokował dyskusję w gwarze, na tematy gwarowe. Udział w niej wzięli rozmówcy z obu stron Olzy (http://gazetacodzienna.pl/node...).

Dołączanie, w celach edukacyjnych, słownika wyrażeń gwarowych, realizowane jest i na innych portalach, porównajmy fragment tekstu gwarowego $\mathrm{z}$ portalu radia lokalnego Istebna:

Ći worce być kocurym ? / Kocurym worce być - dyć na gazdówce wsiyndy pełno myśi a śćiurów, w sómsiekach tak yny śtabarcuje, rómpluje a trześći. W sypaniach, sóndkach, śpajskach, kumorach ći starych gielatach kany gazda trzimióm śpyrkym, suśióne jabka i śliwki, ći aji łobiyli - same dziury - tak róntujóm ty sakramyncki pśiekrwie - tóź jedzynio ci nie chybi.

Do tekstu dołączono Ślabikorz trudniyjśich słów:

Sómsiek - pomieszczenie na siano lub słomę / Śtabarcować - hałasować metalicznie / Rómplować - synonim śtabarcować, lecz niekoniecznie hałas metaliczny / Sypaniaskrzynia na zboże / Sóndek - drewniane duże naczynie na zasoloną słoninę (http:// www.radioistebna.pl...)

Podobną funkcję spełniają inne pomoce dydaktyczne, powstające wspólnym trudem internautów. Są to przede wszystkim różnego typu słowniki gwarowe, począwszy od wikisłownika - strony z dialektyzmami polskimi ze Śląska Cieszyńskiego, z dołączonymi odpowiednikami ogólnopolskimi (https://pl.wiktionary...), opartej na źródłach pisanych, skończywszy na amatorskich "projektach”, ale o dużych walorach poznawczych, jak na przykład na stronie autorskiej Tomasza Sochackiego (https://www.gwaracieszynska...) z polskiej części regionu, czy na podstronie http://www.isibrno.cz/ malczyk/karwinal.htm, Romana Malczyka, z części czeskiej (http://www.isibrno...).

Należy jednak brać pod uwagę fakt, że w świecie wirtualnym zacierają się granice między komunikacją oficjalną i nieoficjalną. Obok komunikatów prasowych w rozumieniu klasycznym, prasy drukowanej, w Internecie funkcjonują ich elektroniczne odpowiedniki. Wydania elektroniczne w takich wypadkach, jako mutacje wydań drukowanych, podlegają podobnym uwarunkowaniom jak media klasyczne, na przykład genologicznym, ze świadomością potrzeby odróżniania informacji od komentarza (choć już niekoniecznie ze stosowaniem się do tej reguły). Obok tego jednak pojawiły się w sieci gatunki medialne specyficzne dla wydań elektronicznych, jak blogi i video-blogi. Tematyka i sposób ich prowadzenia daje świadectwo aspiracji autorów do oficjalizacji wypowiedzi. Jednocześnie, $\mathrm{w}$ warstwie formalnej, często są one bliskie wypowiedziom potocznym. Czasem są to tylko wpisy gwarowe w blogu prowadzonym w języku ogólnopolskim, np. 
Dzisio zaś na drugą strone Olzy. Pojechołem do Bystrzycy i wyjechołem se na Pasieki. Kaj sie nie obejrzysz tam "naszo” cieszyńska gwara./ Jak chcecie kiedy posłuchać tej naszej mowy to sie wybiercie kiedy do Bystrzycy albo do Gródka. Na Pasiekach fajnie żech se pogodoł z jednym starszym panoczkiem co tam miyszko, mo też rad bicykiel i trekingi po groniach (http://daniel3ttt...).

Bywają jednak i blogi pisane kodem nieoficjalnym, urzędowo niepotwierdzonym, w naszym wypadku gwarą cieszyńską (zob. niżej). Blogi stanowią więc naturalny pomost do komunikacji o charakterze nieoficjalnym, czasem prywatnym. W tym wypadku, użycie kodów nieoficjalnych jest w pełni uzasadnione. Różnica w stosunku do komunikacji potocznej w świecie realnym polega jedynie na tym, że sytuacja komunikacyjna ma charakter najczęściej otwarty, na wirtualnym forum publicznym. Nie oznacza to, że nie ma mechanizmów ograniczania tego forum lub kontrolowania składu grupy komunikującej się. Najprostszym przykładem są zamknięte grupy dyskusyjne, z koniecznością logowania się, a nawet uzyskania zgody na udział w grupie przez dysponenta praw - administratora. Bywają oczywiście grupy dyskusyjne i fora internetowe ogólnodostępne, np. forum na portalu Śląska Cieszyńskiego: www.ox.pl.

W tego typu komunikacji gwara pojawia się jako kod nieoficjalny, ale i tam musi konkurować z innymi kodami - oficjalnymi, najczęściej w odmianach potocznych, ale i z nieoficjalnymi, np. socjolektami lub profesjolektami. W dużej mierze wybór określonego kodu nieoficjalnego zależy od tematyki tekstów. I tak w dyskusjach internetowych toczonych na tematy młodzieżowe istnieje naturalna tendencja do stosowania slangizmów młodzieżowych. Kod gwarowy przywoływany jest w wypadkach, gdy tematyka tekstu, zwłaszcza dyskusji internetowych, dotyczy spraw regionu cieszyńskiego. Prawie wyłącznie dyskusja prowadzona jest w gwarze cieszyńskiej, gdy tematem jest sama gwara, tak na www.ox.pl (np. http:// forum.ox.pl/showthread...) , ale już na forum istebna.com w wątku na temat gwary gwarzyni, przeważa dyskusja w języku ogólnopolskim (http://forum.istebna...).

Udział gwary w tego typu komunikacji ma charakter skalowalny - od kodu prowadzenia strony: monologowej lub dialogowej / polilogowej, do, na drugim krańcu, jedynie cytatów, czasem w funkcji nazw własnych, przezwiskowych (zob. niżej).

Rozpatrując funkcjonowanie kodu gwarowego w Internecie możemy dojść do wniosku, że niejako wzorowe użycie gwary w sieci stanowią strony z zamierzenia pisane gwarą cieszyńską ${ }^{2}$. Od znajomości gwary i stopnia jej czynnego opanowania zależy, czy jest to też użycie wzorcowe. Za takie można uznać stronę autorską Tomasza Sochackiego, w zamierzeniu w całości tworzoną w gwarze cieszyńskiej, o stosunkowo rozwiniętej strukturze i zróżnicowanej treści

$2 \mathrm{~W}$ ostatnim czasie ten gatunek internetowy jest jednak w odwrocie, $\mathrm{w}$ związku z polityką właścicieli portali użyczających miejsca i adresów internetowych. 
(https://gwaracieszynska.pl/). Najczęściej jednak mamy do czynienia z różnymi stopniami „samodzielności kodowej” produkowanych tekstów - od tekstów bliskich klasycznej formie gwary, takiej, jak ją opisują opracowania dialektologiczne, po teksty zmienione pod kątem przynależności grupowej użytkownika, z elementami $\mathrm{z}$ innych kodów (np. slangu młodzieżowego), aż po teksty formalnie mieszane, choć w intencjach autorów gwarowe - „po naszymu”. Analiza formalna tekstów gwarowych, w gwarze cieszyńskiej, pojawiających się w Internecie, pokazuje ten mieszany charakter analizowanego zjawiska, zob. np. Greń (2007a). Można tu więc znaleźć teksty, w których widać dążenie do zachowania poprawności normy gwarowej, przez co należy rozumieć utrwaloną w świadomości użytkowników i przekazaną przez tradycję postać gwary. Dążenie do komunikacji w takim właśnie kodzie widać przede wszystkim w niektórych blogach i w dyskusjach z zamierzenia prowadzonych w gwarze i o gwarze. Podobnie wypowiedzi i teksty gwarą, funkcjonujące w postaci cytatu gwarowego, mogą wykazywać starania użytkowników do zgodności formalno-funkcjonalnej z tradycją. Chodzi o te przypadki, gdy gwara i formy gwarowe stają się tematem rozważań prowadzonych $w$ języku standardowym, $w$ formie pisanej, ale i w nagraniach video, np. w wywiadach na temat gwary cieszyńskiej, wykonanych przez portal ox.pl, a udostępnionych na youtube.com.

Po drugiej stronie na skali „poprawności historycznej” znajdują się przypadki, w których użycie gwary wynika jedynie ze względów czysto praktycznych. Możemy tu mieć do czynienia z dwoma przypadkami. Po pierwsze, chodzi o przypadki gwary jako kodu najbliższego dla autora wypowiedzi internetowej, najłatwiejszego w użyciu. Z takimi przypadkami mamy do czynienia przede wszystkim w czeskiej części Śląska Cieszyńskiego, zob. (Greń 2007a). Mieszany charakter tego typu tekstów szczególnie wyraźnie jest widoczny w blogach Cieszyniaków z czeskiej części Śląska Cieszyńskiego, porównajmy:

Nima nadto / Rubryka Úlety... aneb jak se wygnyć srereotypowi / umieć se wyrobić własnóm aspiryne:-) / Na lekcji se nóm ji podarziło wyrobić $90 \%$ „teoretického výtěžku", także aj po strónie uczóncych, aj po naszej, była spokojenost, jyny nie wiym jak insi, ale jo by nimiała odwagi to prubnyć, jeśli to funguje;) Heh, ni żebych zpochybniowała kwalite własnej pracy, ale podle tego, coch tam wszystko do tego zamiyszała (trza kyselina sírová, kiero se niby niała odfiltrować, także w kóńcowym produkcie nie była, ale kto wiy:) ), tak nie wiym, nie wiym:-) Ale przi biydzie...:-D / Także gdyby był gdosi ochotny otestować tyn biolutki krystaliczny pruszek, tak Wóm pak powiym, jak to dopadło ;-) (http://palili...)

Podobnie, chociaż w dużo mniejszym stopniu:

Je żech drugi notoryk świata / wtorek 28.11.2006 00:05 / Nie wierzicie? Aż do fczora żech to sóm nie wiedzioł. Pióntkowe targniyńci własnego piwnego rekordu żech broł 
jako wyjóntkowy wyczyn, kiery se nimo okazje hned tak powtórzyć (mamuś, to podkreślóm głównie kfuli Ciebie (https://www.chesio...).

Teksty te często oddają mieszany charakter kodu młodzieżowego i to niezależnie od nastawienia autora. W tekstach osób celowo, ale ze względów praktycznych, piszących gwarą, pełno jest zapożyczeń z innych kodów: języka standardowego i slangu młodzieżowego, czeskich, po stronie czeskiej, zob. Greń (2007a) i polskich, po polskiej stronie. Jeżeli zaś autor zamierza pisać polskim językiem potocznym, przepuszcza w swoim tekście, obok slangizmów młodzieżowych, dialektyzmy cieszyńskie, czasem nie rozróżniając pochodzenia tych elementów traktowanych przezeń jako ekspresywizmy.

$\mathrm{Z}$ drugiej zaś strony mamy do czynienia $\mathrm{z}$ sytuacją, gdy gwara, a właściwie gwarowy materiał językowy, staje się celowym środkiem stylistycznym, wzbogacającym wypowiedź na równych prawach z innymi środkami stylistycznymi, jak np. slangizmy czy anglicyzmy, por. Greń (2000). W takim wypadku jednak, obok przyczyn praktycznych, rolę grają względy estetyczne - atrakcyjność wykorzystanego dialektyzmu. I tak na wspomnianym już portalu regionalnym www. ox.pl w tekście oficjalnym pojawia się dobrze znane określenie:

Zapraszamy na kolejną część cyklu - „Najmłodsi stela” - czyli fotogalerię najmłodszych mieszkańców naszego powiatu w obiektywie naszego fotoreportera (https:// wiadomosci...).

Ten sam mechanizm, podnoszenia atrakcyjności stylistycznej, wchodzi w grę, gdy, często, jest to wykorzystywane jako sposób na podniesienie własnej atrakcyjności językowej rozmówcy, w postaci wyrazistego nicku gwarowego, z gwarowymi cechami fonetycznymi: grandziorz, łobeznany, toblotany, mondrok, wygodany, leksykalnymi: fafla, ganc szaszek, gizd, ludź stela, mamlasek, pyrczek, i leksykalnymi w fonetycznej formie gwarowej: boroczek, chroboczek, drzistok, fulok ${ }^{3}$.

$\mathrm{Na}$ uboczu owych internetowych zastosowań gwary cieszyńskiej lokują się przypadki odtwarzania tekstów gwarowych powstałych bądź to z przeznaczeniem do umieszczenia $\mathrm{w}$ Internecie, jak $\mathrm{w}$ wielkiej bibliotece, fonotece i filmotece, bądź to powstałe poza środowiskiem wirtualnym, a potem reprodukowanych w bazach internetowych. W pierwszym wypadku chodzi o nagrania z przeznaczeniem umieszczenia ich w dostępie otwartym, na przykład na youtube.com. Przykładem tego typu jest amatorskie nagranie terenowe wywiadu gwarowego z Jaworzynki (https://www.youtube.com...), które nota bene stało się impulsem do dyskusji, raczej amatorskiej, na temat gwary. W drugim wypadku chodzi o publikacje dialektologiczne: opracowania naukowe i teksty oraz nagrania wideo, na przykład z konkursów znajomości gwary (https://youtu.be/...).

\footnotetext{
3 Wszystkie przykłady z forum na portalu regionalnym ox.pl [dostęp: 2013, 2015].
} 
Wprawdzie w ich przypadku sieć spełnia de facto funkcję tablicy ogłoszeniowej, to jednak nie pozostaje to bez wpływu na funkcjonowanie gwary w komunikacji internetowej. Po pierwsze, dostarczają one materiału tematycznego, do analizy i rozważań dla świadomych internetowych analityków gwary, po drugie, prezentują wzorce gwarowe dla tych, dla których „prawidłowa” forma gwarowa stanowi problem do rozwiązania lub cel dążeń.

Podobną funkcję spełniają internetowe wersje tradycyjnych mediów, w których również znaleźć można, teksty i fragmenty tekstów w gwarze cieszyńskiej, funkcjonujące na prawach cytatu. Oto przykład z czasopisma „Nasza Trójwieś”:

Urszula Gruszka opowiedziała z kolei o wzruszających okolicznościach śmierci Jana Kawuloka: „Przyjechali my rano z zespołym z Cepeliady, a chłapciska pomogali instrumenty smycić ku chałpie. Jak jedyn wsiecy my pośli przed dźwiyrze do ujca Kawuloka i cały autobus przyszeł, zaspiywalimy kurpiowską pieśń, kierej nas tam naucili. Tak jakoby zespolocy wiedzieli, zie ich trzeba poziegnać i to było ich łostatni poziegnani. Na drugi dziyń ujec uż nie zili. [...]” (Nasza Trójwieś, nr 11).

Podobnie należy traktować krótkie opowiadanie gwarą jabłonkowską, Małgorzaty Kiereś, pt. Jankowe zolety, opublikowane w tymże czasopiśmie (Nasza Trójwieś, nr 1).

W takim wypadku na informatorów czyhają jednak zasadzki, wynikające z nieznajomości gwary administratorów portali. Oto na przykład informacja o konkursie na znajomość gwary, jak można się domyślić cieszyńskiej, w Zespole Szkół Ekonomiczno-Gastronomicznych im. W. Szybińskiego w Cieszynie, na portalu szkolnym opatrzona została przez administratora strony tekstem wiersza Pan Hilary w przekładzie Marka Szołtyska na śląszczyznę Górnego Śląska, a więc z cechami językowymi obcymi dla gwar Śląska Cieszyńskiego (http://szybinski ...).

Podsumowując, możemy stwierdzić, że w wielogłosowej rzeczywistości komunikacji internetowej istnieje miejsce do komunikacji z wykorzystaniem gwary cieszyńskiej. Ułatwia to duża rozpiętość formalno-funkcjonalna i społeczna komunikacji internetowej. Zróżnicowanie formalne tekstów gwarowych w dużej mierze odbija współczesne zróżnicowanie wykorzystania gwary cieszyńskiej w świecie realnym. Działają tu też podobne mechanizmy, np. stylizacji wypowiedzi ${ }^{4}$. W związku z dużą anonimowością niektórych typów wypowiedzi, teksty gwarowe w Internecie mogą mieć nawet bardziej naturalny charakter niż teksty w świecie realnym.

Na Śląsku Cieszyńskim, jak dotychczas, nie zarejestrowałem prób całkowitej oficjalizacji dialektów cieszyńskich, na przykład w postaci śląsko-cieszyńskiej

4 Zostało to sprawdzone w anonimowym teście na znajomość gwary u młodzieży cieszyńskiej, zob. Greń (1997), tam też opis stylizacji w języku młodzieży z wykorzystaniem elementów gwarowych. 
Wikipedii, choć już Wikisłownik uwzględnia cieszyńską, gwarową (!) „samodzielność leksykalną" (https://pl.wiktionary...). Najbliższa temu jest wspomniana wyżej strona autorska Tomasza Sochackiego. Cieszyńskie podłoże gwarowe jest brane pod uwagę w projekcie tworzenia języka (górno)śląskiego, lecz zarówno ewentualna zasadność tego, jak i sposoby realizacji, stanowią odrębny problem dialektologiczny i etnolingwistyczny.

\section{Bibliografia}

\section{Źródła internetowe:}

http://daniel3ttt.bikestats.pl/891632,Bystrzyca-Na-Pasiekach.html (zapis z dnia:

Poniedziałek, 25 marca 2013 | dodano: 25.03.2013) [dostęp: 21.10.2018].

http://forum.istebna.com/viewtopic.php?t=36\&postdays=0\&postorder=asc\&start=15

[dostęp: 19.10.2018].

http://forum.ox.pl/showthread.php?6177-Pogwarzmy-se-tak-jak-nasze-starki-i-starziki

[dostęp: 19.10.2018].

http://gazetacodzienna.pl/artykul/wydarzenia/co-tydziyn-po-naszymu-rozkazowac-to-

kazdy-poradzi-ale-poschlocha-mao-gdo [dostęp 19.10.2018]. http://gazetacodzienna.pl/node/90485 [dostęp: 20.10.2018].

http://palili.bloguje.cz/index.php / /Witóm całóm kitóm !.html [dostęp: 29.11.2006]. http://szybinski.cieszyn.pl/szybinski_new/content/tyn-mo-godane, wiadomość z dnia:

11.11.2014 [dostęp 19.10.2018]. http://www.isibrno.cz/ malczyk/slownik.htm [dostęp: 25.10.2018]. http://www.radioistebna.pl/kultura/item/827-z-goralskich-rozmyslan $\quad 7.02 .2018$ [20.10.2018].

http://www.radioistebna.pl/regionalne/proza-regionalne/item/528-cim-worce-byc-gazdowski-dumania [dostęp 19.10.2018]. http://zwrot.cz/2016/09/trucina-po-naszymu/ [dostęp: 21.10.2018]. https://pl.wiktionary.org/wiki/Kategoria:Dialektyzmy_polskie_-_\%C5\%9Al\%C4\%85sk_

Cieszy\%C5\%84ski [dostęp: 19.10.2018]. https://wiadomosci.ox.pl/konkurs-gwary-slaska-cieszynskiego-rzondzymy-po-naszymu,52368 [dostęp 7.06.2016]. https://wiadomosci.ox.pl/konkurs-gwar-znamy-wyniki,24991 [dostęp 23.11.2013]. https://wiadomosci.ox.pl/najmlodsi-stela-797032018,54144 [dostęp: 19.10.2018] https://wiadomosci.ox.pl/spotkanie-sekcji-milosnikow-gwary,42263 [dostęp 7.09.2016]. https://www.chesio.com/ /chesterów blog.htm [dostęp: 29.11.2006]. https://www.gwaracieszynska.pl/s\%C5\%82ownik-gwary [dostęp: 19.10.2018]. https://www.youtube.com/watch?v=UWH3W54LdVM [dostęp: 19.10.2018]. https://youtu.be/ecdrv5nDOCQ [dostęp: 19.10.2018]. pl.wiktionary.org [dostęp: 19.10.2018]. 


\section{Literatura:}

Greń Zbigniew, 1997, Gwara cieszyńska najmłodszej generacji. Stopień znajomości i sposób wykorzystania leksyki gwarowej, [w:] Leksyka słowiańska na warsztacie językoznawcy, red. Hanna Popowska-Taborska, Warszawa, s. 75-89.

Greń Zbigniew, 2000, Śląsk Cieszyński. Dziedzictwo językowe, Warszawa.

Greń Zbigniew, 2000a, Socjolingwistyczne uzupełnienie i weryfikacja dialektologicznych badań arealnych (na materiale gwar cieszyńskich), „Studia z Filologii Polskiej i Słowiańskiej”, t. XXXVI, s. 41-63, Warszawa.

Greń Zbigniew, 2006, Stałość versus zmienność dialektów cieszyńskich, „Studia z Filologii Polskiej i Słowiańskiej”, t. XLI, s. 45-58, Warszawa.

Greń Zbigniew, 2007, Po śląsku w Internecie. Problemy standaryzacji żywiołowej, [w:] Z polskich studiów slawistycznych, seria 11, Językoznawstwo, red. Zofia RudnikKarwatowa, Warszawa, s. 61-68.

Greń Zbigniew, 2007a, Język młodzieży z Zaolzia w Internecie, „Prace Filologiczne”, t. LIII, s. 231-240, Warszawa.

Greń Zbigniew, 2008, Śląska lokalność w Internecie, [w:] Oblicza lokalności. Ku nowym formom życia lokalnego, red. Joanna Kurczewska, Warszawa.

Grzenia Jan, 2006, Komunikacja językowa w Internecie, Warszawa.

Jagodzińska Joanna, 2002, Dyskurs internetowy, [w:] Czynności tworzenia i rozumienia wypowiedzi, red. Józef Porayski-Pomsta, Warszawa, s. 207-227.

Mętrak Maciej, 2014, Zachodniosłowiański internet mniejszościowy - medium masowe czy hobby pasjonatów, „Zeszyty Łużyckie”, t. XLVIII, s. 329-344, Warszawa.

Nasza Trójwieś, nr 11 (291), r. XXVI, listopad 2017, za: www.istebna.eu [dostęp: 19.10.2018].

Nasza Trójwieś, nr 1 (282), r. XXV, styczeń 2017, za: www.istebna.eu [dostęp: 19.10.2018]. Osowski Błażej, 2018, Gwary słowiańskie w nowym środowisku komunikacyjnym Internet, $[w]$ : Z polskich studiów slawistycznych, seria 13, t. 2, red. Zbigniew Greń, Poznań, s. 223-232.

\section{Streszczenie}

Celem artykułu jest analiza obecności gwar cieszyńskich w najnowszym medium elektronicznym - w Internecie. Z jednej strony zależy nam na wydobyciu funkcji, jakie spełnia ten kod, zarówno w użyciu prymarnym, jak i sekundarnym, w drugim zaś o ogólną analizę formalną wypowiedzi gwarowych i wypowiedzi o różnym stopniu nasycenia elementami gwarowymi. Teksty gwarowe i z wykorzystaniem gwary wykazują duże zróżnicowanie, tak pod względem funkcjonalnym, jak i formalnym. Mamy tu do czynienia zarówno z tekstami zredagowanymi, jak i tekstami pojawiającymi się ad hoc, czasem wręcz żywiołowymi. Jednocześnie, dzięki stosunkowo dużej anonimowości wypowiedzi spontanicznych mogą one w naturalny sposób odsłaniać rzeczywistą znajomość i funkcjonalność tego kodu u przedstawicieli różnego typu użytkowników gwary. 